\title{
Population structure in the freshwater shrimp (Paratya australiensis) inferred from allozymes and mitochondrial DNA
}

\author{
DA Hurwood ${ }^{2,3}$, JM Hughes ${ }^{1,2}$, SE Bunn ${ }^{1,2}$ and C Cleary ${ }^{2}$ \\ ${ }^{1}$ Co-operative Research Centre for Freshwater Ecology, Australia; ${ }^{2}$ Australian School of Environmental Studies, Griffith University, \\ Nathan, Queensland 4111, Australia
}

In 1995, an allozyme study was conducted on the genetic structure of a population of the common atyid shrimp, Paratya australiensis, in the Conondale Range, south-eastern Queensland with two subcatchments each within two river drainages sampled. The allozyme study revealed a high degree of population structure, with the data interpreted as reflecting a pattern of restricted contemporary gene flow, primarily between streams within subcatchments. High levels of differentiation occurred between all subcatchments. In this study, we analysed a partial fragment of the mitochondrial COI gene in order to further test and verify these results. The mtDNA data largely conflicted with the hypothesis of restricted gene flow indicating that contemporary dispersal was highly unlikely, even between streams within subcatchments, with many sites fixed for unique mtDNA haplotypes. Additionally, the level of divergence between the Stony Creek subcatchment and all other sampling sites indicated that it had been isolated for approximately 2-3 million years, while low levels of divergence were detected across the Conondale Range between the Kilcoy and Booloumba Creek subcatchments. The sharing of alleles at certain allozyme loci between all subcatchments is, therefore, likely to be the result of ancestral retention and possibly because of the effects of balancing selection.

Heredity (2003) 90, 64-70. doi:10.1038/sj.hdy.6800179

Keywords: Paratya australiensis; gene flow; dispersal; allozymes; mtDNA; balancing selection

\section{Introduction}

The indirect method of inferring rates of gene flow/ dispersal by comparing nuclear allele frequencies between populations (Slatkin, 1981) has been used widely for the past two decades. The underlying theory is that high levels of gene flow lead to genetic homogeneity, whereas restricted gene flow results in differentiation between isolated populations. Recently, however, Templeton (1998) highlighted the inherent problems associated with using nuclear allele frequencies (particularly allozymes) to infer the amount of gene flow from levels of genetic differentiation using $F$-statistics $\left(F_{\mathrm{ST}}\right)$ between populations. An $F_{\mathrm{ST}}$ greater than zero, but less than one, has been interpreted as a function of restricted contemporary gene flow. When two populations share a common allele, regardless of the respective allele frequencies, the resulting $F_{\mathrm{ST}}$ will be less than one, indicating some degree of gene flow. Yet, this scenario can also arise from the retention of ancestral genes in two totally isolated populations, from a time when gene flow was occurring. If there has not been sufficient time for random genetic drift to sort alleles into fixed differences

Correspondence: DA Hurwood, Australian School of Environmental Studies, Griffith University, Nathan, Queensland 4111, Australia. E-mail:d.hurwood@qut.edu.au

${ }^{3}$ Current Address: School of Natural Resource Sciences, Queensland University of Technology, Gardens Point, Brisbane, Queensland 4000, Australia

Received 27 December 2001; accepted 19 August 2002 in respective subpopulations or there is strong selection for particular alleles across the population, then ultimately this situation will arise.

Naturally, extremely high $F_{\mathrm{ST}}$ values $(\mathrm{eg}>0.5$ ) would generally be regarded as an indication of zero gene flow without independent data to the contrary. One way of overcoming this problem, in the absence of such information, is by utilising the characteristic high mutation rate, maternal inheritance and haploid nature of mitochondrial DNA (mtDNA).

This study focuses on the comparison of nuclear and mitochondrial genes in a population of the freshwater shrimp, Paratya australiensis (Kemp). Hughes et al (1995) conducted an allozyme survey of subpopulations from headwater sites in two major river drainages (the Brisbane and Mary Rivers) that drain either side of the Conondale Range, south-eastern Queensland, Australia (Figure 1). Three sites within each of two subcatchments were sampled for both rivers. Additionally, lowland confluence sites were sampled for each subcatchment. The general conclusion from this study was that contemporary gene flow among sites was restricted, especially where a significant elevation difference existed between sites and their respective confluences. However, the expected pattern reflecting the stream hierarchy model of gene flow (Meffe and Vrijenhoek, 1988) was not observed primarily because of greater levels of differentiation between subcatchments within a single drainage than among the two river systems. Nevertheless, the least amount of genetic variation was generally seen 


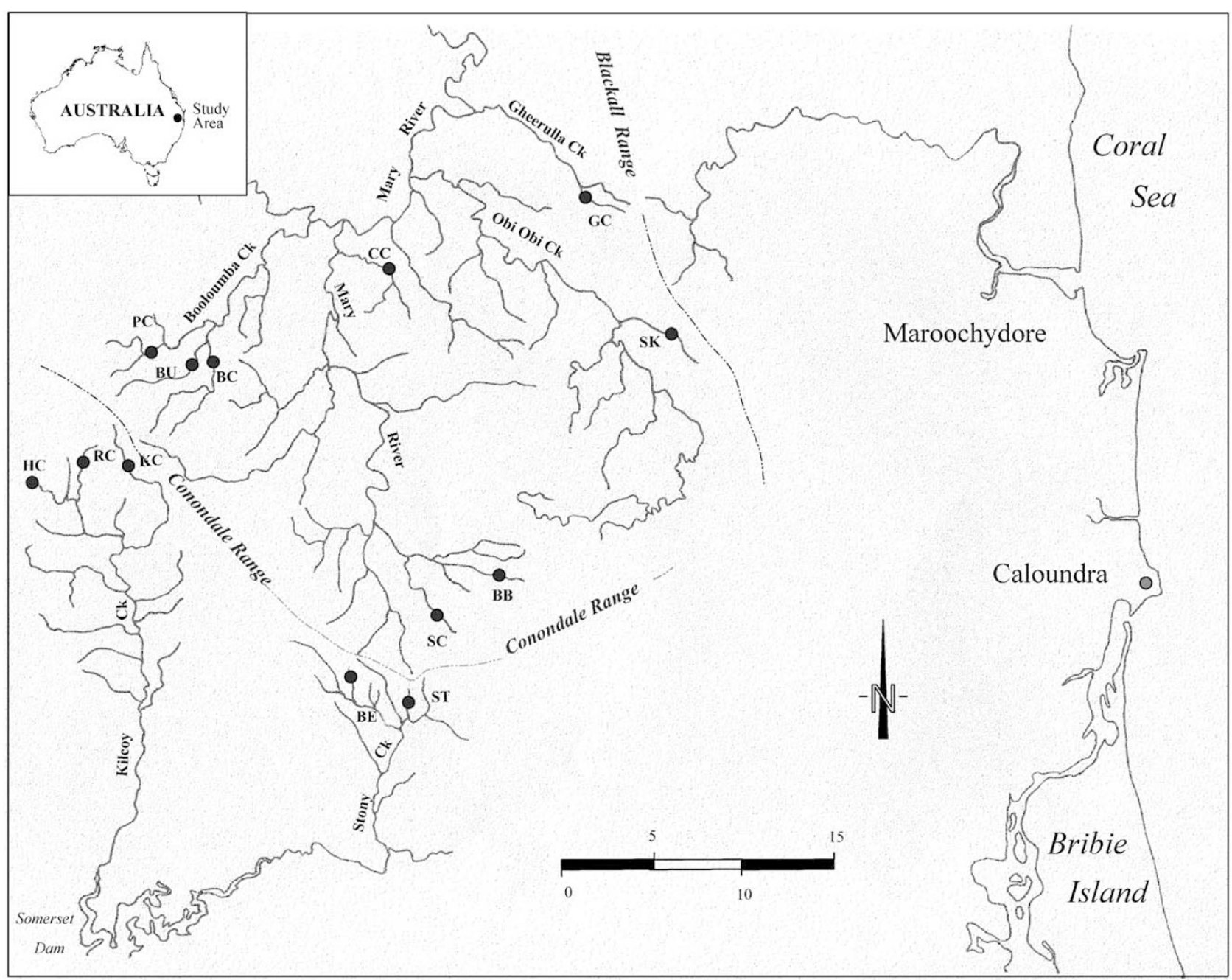

Figure 1 Map showing the sampling sites for P. australiensis from the Conondale and Blackall Ranges. Site abbreviations are: Booloumba Ck. (BC); Bundaroo Ck. (BU); Peters Ck. (PC); Scrub Ck. (SC); Broken Bridge (BB); Chinaman Ck. (CC); Skene Ck. (SK); Gherulla Ck. (GC); Kilcoy Ck. (KC); Rum Crossing (RC); Humbug Ck. (HC); Stony Ck. (ST); and Branch Ck.East (BE).

between streams within subcatchments (ie, the lowest hierarchical level), as predicted by the stream hierarchy model. The subsequent interpretation of these data was that contemporary gene flow was highly restricted between most sites but the highest amount of dispersal was between streams within subcatchments. $F_{\mathrm{ST}}$ values ranged from 0.023 in the upper Mary to 0.431 in the Kilcoy subcatchment. The mean of these values (0.192) is large compared to freshwater fish species (HernandezMartich and Smith, 1990).

Three hypotheses were originally put forward to account for the non-hierarchical gene flow patterns. Both the ideas of terrestrial dispersal and balancing selection were largely rejected. The third hypothesis considered the relationship between the inferred pattern of gene flow and the variability at a particular locus. The fewer the number of alleles per locus, the greater the probability of two sites currently sharing alleles by chance, even after long periods in isolation. If this was the case, then loci with greater levels of variation would be less likely to display shared alleles in isolated populations. This hypothesis is supported at the Mpi-1 locus that displayed the greatest allelic diversity and consistently had higher levels of differentiation between subcatchments.

The general aim of this study was to assay the same subpopulations of shrimp using mtDNA sequence analysis in order to test the hypotheses arising from the allozyme survey. More specifically, the aim was to ascertain the relative likelihood of contemporary restricted gene flow as opposed to the retention of ancestral alleles in determining the observed genetic structure of this population.

\section{Methods}

\section{Study species and sampling sites}

$P$. australiensis is a species of small freshwater atyid shrimp common to streams of the east coast of Australia. In south-eastern Queensland they appear to be predominantly restricted to the headwater streams that flow easterly to the coast. The sampling sites are as per Hughes et al (1995). Three additional sites were sampled in 1996 for allozyme analysis from the Blackall Range that also drains into the Mary River (Figure 1). The same sites were resampled in 2000 for mtDNA analysis. 


\section{Allozymes}

Results presented here contain data that are already published by Hughes et al (1995) as well as additional samples taken from the Blackall Range. Five variable enzymes were detected resulting in six variable loci (Appendix 1). Electrophoretic techniques were as per Hughes et al (1995).

\section{Mitochondrial DNA extraction and PCR}

Mitochondrial DNA was extracted from muscle tissue of up to 24 individuals from each site using the alkaline lysis protocol outlined in Tamura and Aotsuka (1988). The fragment of mtDNA used in this study was a partial sequence of the protein coding cytochrome oxidase subunit I (COI) gene. Primers LCO-1490 and HCO-2198 (Folmer et al, 1994) were used to amplify approximately $670 \mathrm{bp}$. Reactions contained $30 \mathrm{nmol}$ each of dATP, dGTP, dCTP and dTTP (Promega), 2 units of Taq DNA polymerase (Biotech), $2.5 \mathrm{mmol} \mathrm{MgCl}_{2}, 5-\mu \mathrm{l}$ of $10 \times$ polymerase reaction buffer (Biotech), $1.0-\mu$ mol of each primer, $0.2-\mu \mathrm{g}$ of template DNA, and adjusted to a final volume of $50 \mu \mathrm{l}$ with $\mathrm{ddH}_{2} \mathrm{O}$. DNA was initially denatured at $95^{\circ} \mathrm{C}$ for $5 \mathrm{~min}$, then 15 cycles of $95^{\circ} \mathrm{C}$ denaturing for $30 \mathrm{~s}, 40^{\circ} \mathrm{C}$ annealing for $30 \mathrm{~s}$ and $72^{\circ} \mathrm{C}$ extension for $1 \mathrm{~min}$. The annealing temperature was then raised to $55^{\circ} \mathrm{C}$ for another 20 cycles with denaturing and extension temperatures as before.

Temperature gradient gel electrophoresis combined with heteroduplex analysis (TGGE-HA) was used to screen for variation in the amplified products (DIAGEN $\mathrm{GmbH})$. The TGGE method relies on the physical properties of the mtDNA fragment (ie relative melting temperatures of different mtDNA sequences) and how they react when run through a linear temperature gradient. Details regarding this technique are provided by Lessa and Applebaum (1993) and Campbell et al (1995). The reference individual used for heteroduplexing was from the Stony Creek site. The specific methodology used is outlined in Hurwood and Hughes (1998). The optimal conditions identified for the TGGE analysis consisted of a gradient of $27-45^{\circ} \mathrm{C}$ for which the samples were run at $300 \mathrm{~V}$ for $2.75 \mathrm{~h}$. The resulting banding pattern was visualised with silver staining (DIAGEN).

Three individuals of each putative haplotype identified by TGGE-HA were sequenced per site. PCR product was cleaned using Qiaquick columns (Qiagen) following the manufacturer's specifications. Sequencing reactions were carried out using Big-Dye terminator cycle sequencing reactions (Perkin Elmer) as per the manufacturer's instructions along with approximately $30 \mathrm{ng}$ of clean DNA template and 3.2 pmol of primer on an Applied Biosystems 377 automated sequencer. Both heavy and light strand were sequenced for each individual.

\section{Statistical analysis}

A neighbour joining tree was constructed from the allozyme data, based on Cavalli-Sforza and Edwards (1967) chord distance, using PHYLIP (version 3.57c) (Felsenstein, 1995) in order to show the relationship between sampling sites. The relationship between mtDNA haplotypes was displayed with a minimum spanning cladogram estimated using the TCS program (Clement et al, 2000) that provides the $95 \%$ parsimoniously plausible branch connections between haplotypes. A population tree with bootstrap support for the mtDNA data was not appropriate because of the extremely low variation within sampling sites. Consequently, a haplotype neighbour joining tree was generated using the Kimura 2-parameter distance method (Kimura, 1980) in MEGA 2 (Kumar et al, 2001), with bootstrap values estimated from 1000 replications.

\section{Results}

\section{Allozymes}

Sample size and allele frequency for each locus and site are given in Appendix 1. This table includes data from the original study of Hughes et al (1995) as well as data collected from the Blackall Range in 1996. One new allele was detected at low frequency from the additional sites in the Mary River at the Pgm-1 locus. The relationship between the sites is displayed in Figure 2. Although the bootstrap values tend to be relatively low, sampling sites from a given subcatchment tend to group together. The relationship between subcatchments is largely unresolved; hence, there is little support for subcatchments from the same river system grouping together. For example, Stony (ST) and Branch (BE) Creeks are part of the Brisbane River drainage, while the Booloumba subcatchment (BC, BU, PC) flows into the Mary River.

\section{mtDNA}

From a total of 242 individuals from 13 sites screened for variation, 11 putative haplotypes were detected. Direct sequencing of these haplotypes revealed 47 variable sites from the $632 \mathrm{bp}$ analysed (Appendix 2) (Sequences have been submitted to GenBank with accession nos.

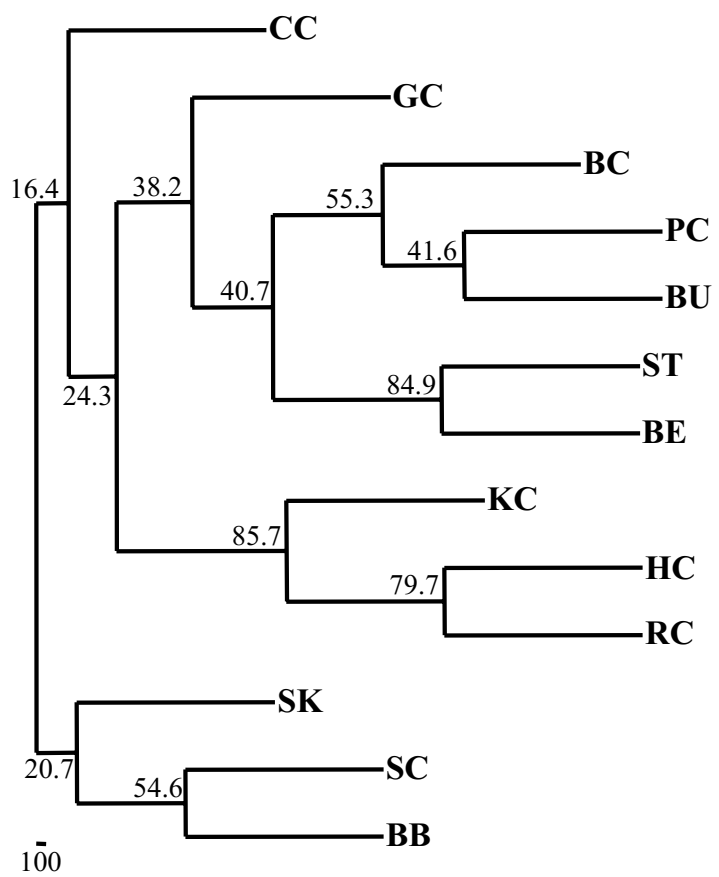

Figure 2 Neighbour joining tree showing the relationship between sites based on allozyme data using Cavalli-Sforza and Edwards chord distance. Bootstrap values were estimated from 1000 replications. Site abbreviations are as per Figure 1. 
Table 1 Haplotype frequency per sampling site for P. australiensis

\begin{tabular}{|c|c|c|c|c|c|c|c|c|c|c|c|c|c|}
\hline \multirow{2}{*}{$\begin{array}{l}\text { Site (n) } \\
\text { haplotype }\end{array}$} & \multicolumn{8}{|c|}{ Mary drainage } & \multicolumn{5}{|c|}{ Brisbane drainage } \\
\hline & $B C(17)$ & $B U(12)$ & $P C(20)$ & SC (24) & $B B(8)$ & CC (24) & SK (6) & GC (16) & KC (24) & $R C(24)$ & HC (24) & ST (19) & $B E(24)$ \\
\hline $\mathrm{Pa} 1$ & 1.0 & 1.0 & & & & & & & & & & & \\
\hline $\mathrm{Pa} 2$ & & & & 1.0 & 1.0 & 0.92 & & 1.0 & & & & & \\
\hline $\mathrm{Pa} 3$ & & & & & & 0.08 & & & & & & & \\
\hline $\mathrm{Pa} 4$ & & & & & & & & & & 1.0 & & & \\
\hline Pa5 & & & & & & & & & 0.08 & & & & \\
\hline $\mathrm{Pa} 6$ & & & 1.0 & & & & & & 0.92 & & & & \\
\hline $\mathrm{Pa} 7$ & & & & & & & & & & & 1.0 & & \\
\hline $\mathrm{Pa} 8$ & & & & & & & 1.0 & & & & & & \\
\hline Pa9 & & & & & & & & & & & & 0.90 & 1.0 \\
\hline Pa10 & & & & & & & & & & & & 0.05 & \\
\hline Pa11 & & & & & & & & & & & & 0.05 & \\
\hline
\end{tabular}

Sample size for each site is given. Site abbreviations are given in Figure 1.

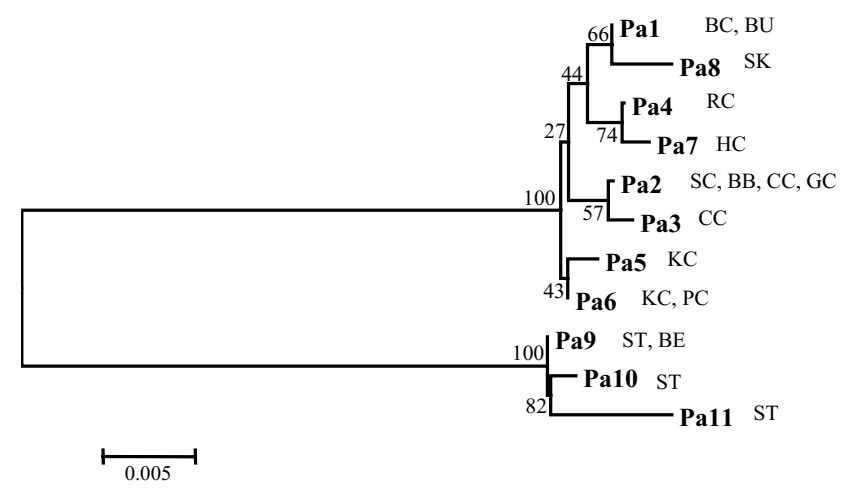

Figure 3 Neighbour joining tree showing the relationship among COI haplotypes for P. australiensis using the Kimura 2-parameter distance method. Sites where haplotypes were sampled are given.

CLADE 1

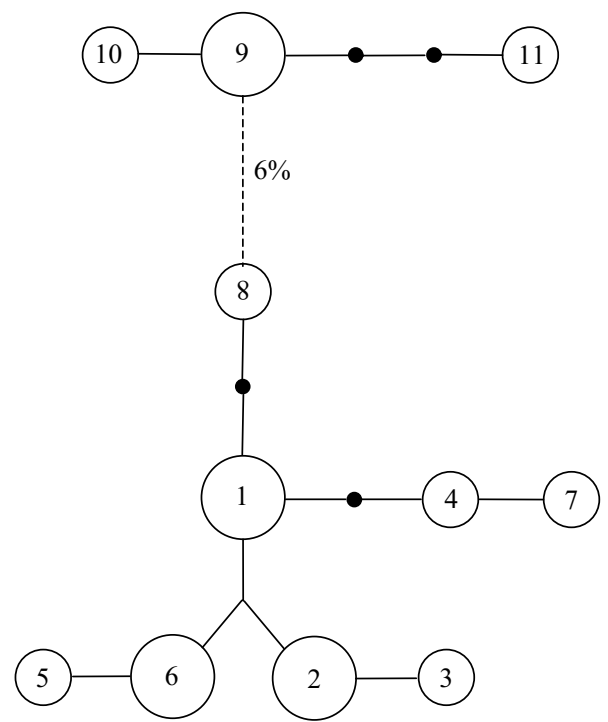

Figure 4 Cladogram depicting the relationship between haplotypes. Circles represent haplotypes, with the larger circles indicating a frequency greater than 25 individuals in the total sample. Black dots represent hypothesised haplotypes that were not detected in the sample.

AF534894-AF534904). The transition/transversion ratio was 2:1. All but one of the transversions were four-fold degenerate and therefore did not change the amino acid.
Haplotype Pa2 was the most common and widespread, being detected in four sites in the Mary River catchment (Table 1). Haplotype Pa6 was the only one that was found on both sides of the Conondale Range (ie in both the Brisbane and Mary Rivers), sampled in Peters (PC) and Kilcoy Creek (KC).

The haplotype cladogram and neighbour joining tree (Figures 3 and 4) reveal two distinct clades. Individuals in Clade 2 were widespread and occurred in both river catchments, while Clade 1 was totally restricted to the Stony Creek subcatchment. Based on a calibrated divergence rate of 2.2-2.6\% for this fragment in Caridean shrimp (Shank et al, 1999), the level of divergence (approximately 6\%) indicates that these lineages split 2-3 million years ago, providing a maximum estimated time the Stony Creek subcatchment has been isolated.

The main difference between the data sets was that there were greater similarities between some sites from different subcatchments for the mtDNA data while subcatchments tended to group together with the allozyme data. For example, Booloumba (BC) and Bundaroo (BU) Creeks were more closely related to Skene Creek (SK), a Blackall site, than to Peters Creek (PC) from their same subcatchment. Furthermore, Peters Creek (PC), a Booloumba site, was fixed for the common haplotype (Pa6) found in Kilcoy Creek (KC) from the Brisbane catchment (Figures 2 and 3). In addition, the subpopulations in the Stony Creek subcatchment are highly divergent based on the mtDNA.

\section{Discussion}

It is apparent from the data presented here that there is no strong congruence in population structure when assayed by allozyme and mtDNA methods. The most notable difference between the two data sets is that sites in the Stony Creek subcatchment appear to have been totally isolated from the surrounding population for approximately 2.5 million years. The allozyme data suggested that this subpopulation was no more divergent than any other in the study.

While the allozyme data indicated restricted gene flow within subcatchments, the mtDNA analysis showed instances where this was not the case, with fixed haplotypic differences within some subcatchments. Therefore, inferring levels of contemporary gene flow between these streams and others in the Conondale 
Range, based on pairwise $F_{\mathrm{ST}}$ values generated from the allozyme data, is clearly inappropriate.

Although the general pattern displayed by the allozymes was one of restricted gene flow within subcatchments, there was a degree of mtDNA haplotype sharing between sites, even from different subcatchments. Haplotype Pa2 was distributed throughout several of the Mary River sites suggesting that the lowland river channel does not present an unfavourable habitat or a barrier to dispersal. The fact that this haplotype was not detected in the Booloumba subcatchment could be a result of the significant change in stream profile acting as a barrier to dispersal to these high altitude sites. Yet, haplotype $\mathrm{Pa} 2$ was found in Gherulla Creek (GC), a site that is also high altitude with significant waterfalls between it and the main river channel.

On a smaller spatial scale, both BC and BU were fixed for haplotype Pa1. The confluence of these sites is once again in the lowland, with the Booloumba Falls separating them. A relatively low level of differentiation from the multilocus allozyme data, even with a high degree of heterozygosity, suggests that this pattern may indeed be the result of contemporary gene flow.

Possibly the most interesting result is the sharing of haplotype $\mathrm{Pa} 6$ between $\mathrm{KC}$ and $\mathrm{PC}$, as these sites are on opposite sides of the Conondale Range. Terrestrial dispersal for this species had been discounted by Hughes et al (1995); however, the possibility of dispersal outside of the stream channel has been proposed to account for the population structure in other atyid shrimps (Hurwood and Hughes, 2001). Additionally, P. australiensis (that show a strong positive rheotactic response) have been observed to climb out of the water when presented with a barrier that impedes their upstream movement (Hancock and Bunn, 1999). Alternatively, haplotype sharing across the range could have resulted from an episode of drainage rearrangement (eg river capture). The geomorphological history with respect to drainage evolution in this area is unknown. Interestingly, a crayfish species (Euastacus hystricosis) shows a similar pattern (M. Ponniah personal communication); however, this distribution supports both the drainage rearrangement and terrestrial dispersal hypotheses.

With consideration of the allozyme data, all of these examples of haplotype sharing may be interpreted as high levels of contemporary gene flow. Certainly, this conclusion appears plausible for the distribution of haplotype Pa2. However, all three shared haplotypes represent internal nodes of the haplotype network (Figure 4). Under coalescent theory, these haplotypes are likely to be older and therefore ancestral to the tip haplotypes (Crandall and Templeton, 1996). This is further supported by their high relative abundance. It is therefore likely that the observed pattern of haplotype sharing is a result of historical gene flow (albeit very recent) with the retention of ancestral types.

The hypothesised historical dispersal may also account for the interdrainage transfer between $\mathrm{KC}$ and PC. The haplotype network provides further information regarding the establishment of these populations. Haplotype $\mathrm{Pa} 6$ is more closely related to $\mathrm{Pa} 1$ and $\mathrm{Pa} 2$ (both from the Mary River catchment) than to haplotypes $\mathrm{Pa} 4$ and $\mathrm{Pa} 7$ detected in the other $\mathrm{KC}$ subcatchment sites (RC,HC). Not only does this indicate that contemporary gene flow is highly unlikely, but also that subpopulations (or haplotypes within them) in this subcatchment have arisen via different evolutionary pathways. One possible explanation is that the ancestral haplotypes $\mathrm{Pa} 1, \mathrm{~Pa} 2$, and $\mathrm{Pa} 6$ were widespread across both sides of the Conondale Range at some stage in the relatively recent past. Subsequent isolation followed by random lineage sorting may explain the pattern currently observed.

The hypothesis of historical interdrainage transfer may also explain the presence of Clade 2 haplotypes in the Kilcoy subcatchment, but does not explain the lack of detection of any individuals bearing a Clade 1 haplotype. However, a translocation study by Hughes et al (in press) has shown that where individuals from both clades are mixed, those in Clade 1 become extinct in less than 10 generations, probably as a result of a combination of asymmetrical mating patterns and the inviability of particular crosses. So it is possible that historically Clade 1 occupied the Brisbane River drainage, but an interdrainage transfer of Clade 2 individuals across the watershed resulted in the extinction of Clade 1 individuals in the Kilcoy subcatchment.

Although historical processes can be invoked to explain these data, this hypothesis does not necessarily exclude the idea that contemporary dispersal occurs among subpopulations of this species in the Conondale and Blackall Ranges. Indeed, both allozyme and mtDNA data support dispersal within the Mary River. For contemporary gene flow to account for the observed pattern however, tip haplotypes in the cladogram should also be seen in more than one site, which is not the case.

There are several explanations for the apparent lack of concordance between the allozyme and mtDNA results. Firstly, the estimations of levels of gene flow between populations can be influenced by sex-biased dispersal. For example, Castella et al (2001) showed that female philopatry in Myotis bats resulted in strong population structure when assayed using mtDNA, yet little structure when observed with nuclear markers because of widespread dispersal by males.

Observational studies, using an experimental stream, showed that all adults, except ovigerous females, showed a positive rheotactic response in $P$. australiensis (Hancock and Bunn, 1999). Larvae were unable to maintain their position, even in very low velocities, but it is likely that both male and female larvae would have the same probability of drifting downstream. Recent analysis from the translocation experiment suggests that although most adult movement is upstream, this is more pronounced in females than males (J Hughes unpublished data). Therefore, it is reasonable to expect that female philopatry is not responsible for the differences between mtDNA and allozyme patterns.

Another possible explanation for the different patterns observed between the allozyme and mitochondrial results is selection. Balancing selection has been invoked to explain the homogeneous allozyme allele frequencies, yet significant mitochondrial and scnDNA divergences in the American oyster, Crassostrea virginica (Karl and Avise, 1992). Similarly, various allozyme loci have been shown to respond to environmental gradients in temperature (Oakeshott, 1976), salinity (Koehn et al, 1980), and heavy metal concentrations (Nevo et al, 1981). Additionally, balancing selection has been demonstrated to maintain reasonably constant allele frequencies across 
sites at specific loci such as Pgi in Colias butterflies (Watt, 1977, 1983). Such selection effects would invalidate the assumption that genetic differentiation among sites represented a balance between genetic drift and gene flow, and could lead to incorrect conclusions on the degree of isolation of particular subpopulations.

The use of multilocus allozyme electrophoresis in population studies, and specifically for the estimation of gene flow, is a powerful tool even with only a few loci (Avise, 1994). However, because of the relatively slow rate of evolutionary change through mutation and drift and the possible effects of balancing selection, the application of allozymes can potentially provide misleading estimations of dispersal between subpopulations. Additionally, these same processes can result in a failure to identify 'Evolutionarily Significant Units' (see Moritz, 1994) as seen in this study.

\section{Acknowledgements}

We would like to thank Mia Hillyer for her help with fieldwork and also Karen Rudkin for some assistance with running samples in the lab. The comments of two anonymous reviewers greatly improved the final manuscript.

\section{References}

Avise JC (1994). Molecular Markers, Natural History and Evolution. Chapman \& Hall: New York.

Campbell NJH, Hartiss FC, Elphinstone MS, Baverstock PR (1995). Outgroup heteroduplex analysis using temperature gradient gel electrophoresis: high resolution, large scale, screening of DNA variation in the mitochondrial control region. Mol Ecol 4: 407-418.

Castella V, Ruedi M, Excoffier L (2001). Contrasted patterns of mitochondrial and nuclear structure among nursery colonies of the bat Myotis myotis. I Evol Biol 14: 708-720.

Cavalli-Sforza LL, Edwards AWF (1967). Phylogenetic analysis: models and estimation procedures. Evolution 21: 550-570.

Clement M, Posada D, Crandall KA (2000). TCS: a computer program to estimate gene genealogies. Mol Ecol 9: 1657-1659.

Crandall KA, Templeton AR (1996). Applications of intraspecific phylogenetics. In: Harvey $\mathrm{PH}$, Leigh Brown $\mathrm{AJ}$ Maynard Smith J, Nee S (eds). New Uses for New Phylogenies, Oxford University Press: Oxford, pp 81-99.

Felsenstein J (1995). Phylogeny Inference Package (PHYLIP) version 3.5c, University of Washington: Seattle, WA.

Folmer O, Black M, Hoeh W, Lutz R, Vrijenhoek R (1994). DNA primers for amplification of mitochondrial cytochrome $c$ oxidase subunit I from diverse metazoan invertebrates. Mol Marine Biol Biotechnol 3: 294-299.

Hancock MA, Bunn SE (1999). Swimming response to watercurrent in Paratya australiensis Kemp, 1917 (Decapoda: Atyidae) under laboratory conditions. Crustaceana 72: 313-323.

Hernandez-Martich JD, Smith MH (1990). Patterns of genetic variation in eastern mosquitofish (Gambusia holbrooki Girard) from the Piedmont and coastal plains of three drainages. Copeia 3: 619-630.

Hughes JM, Bunn SE, Kingston M, Hurwood DA (1995). Genetic differentiation and dispersal among populations of Paratya australiensis (Atyidae) in rainforest streams in southeast Queensland, Australia. J N Am Benth Soc 14: 158-173.
Hughes JM, Goudkamp K, Hurwood D, Hancock M, Bunn S (in press). Translocation causes extinction of a local population of the freshwater shrimp Paratya australiensis (Atyidae). Conserv Biol.

Hurwood DA, Hughes JM (1998). Phylogeography of the freshwater fish, Mogurnda adspersa, in streams of northeastern Queensland, Australia: evidence for altered drainage patterns. Mol Ecol 7: 1507-1517.

Hurwood DA, Hughes JM (2001). Nested clade analysis of the freshwater shrimp, Caridina zebra (Decapoda: Atyidae), from north-eastern Australia. Mol Ecol 10: 113-125.

Karl SA, Avise JC (1992). Balancing selection at allozyme loci in oysters: implications for nuclear RFLPs. Science 256: 100-102.

Kimura M (1980). A simple method for estimating evolutionary rate of base substitution through comparative studies of nucleotide sequences. J Mol Evol 16: 111-120.

Koehn RK, Newell RIE, Immermen (1980). Maintenance of an aminopeptidase allele frequency cline by natural selection. Proc Natl Acad Sci USA 77: 5385-5389.

Kumar S, Tamura K, Jakobsen IB, Nei M (2001). MEGA: Molecular Evolutionary Genetics Analysis software (Version 2.1). Bioinformatics 17: 1244-1245.

Lessa EP, Applebaum G (1993). Screening techniques for detecting allelic variation in DNA sequences. Mol Ecol 2: 119-129.

Meffe GK, Vrijenhoek RC (1988). Conservation genetics in the management of desert fishes. Conservation Biol 2: 157-169.

Moritz C (1994). Defining 'Evolutionary Significant Units' for conservation. Trends Ecol Evol 9: 373-375.

Nevo E, Perl T, Beiles A, Wool D (1981). Mercury selection of allozyme genetypes in shrimps. Experientia 37: 1152-1154.

Oakeshott JG (1976). Biochemical differences between alcohol dehydrogenases of Drosophila melanogaster. Aust J Biol Sci 29: 265-274.

Shank TM, Black MB, Halanych KM, Lutz RA, Vrijenhoek RC (1999). Miocene radiation of deep-sea hydrothermal vent shrimp (Caridea: Bresiliidae): evidence from mitochondrial cytochrome oxidase subunit I. Phylogenet Evol 13: 244-254.

Slatkin M (1981). Estimating levels of gene flow in natural populations. Evolution 47: 264-279.

Tamura K, Aotsuka T (1988). Rapid isolation method of animal mitochondrial DNA by the alkaline lysis procedure. Biochem Genet 26: 815-819.

Templeton AR (1998). Nested clade analysis of phylogeographic data: testing hypotheses about gene flow and population history. Mol Ecol 7: 381-397.

Watt WB (1977). Adaptation at specific loci. I. Natural selection on phosphoglucose isomerase of Colias butterflies: biochemical and population aspects. Genetics 87: 177-194.

Watt WB (1983). Adaptation at specific loci. II. Demographic andbiochemical elements in the maintenance of the Colias Pgi polymorphism. Genetics 103: 691-724.

\section{Appendix 1}

Sample sizes $(n)$, allele frequencies, and heterozygosities (H) for the six allozyme loci for each site (Table 2).

\section{Appendix 2}

Position of variable sites of the 11 haplotypes detected for P. australiensis. Dots indicate homology to Pa1 (Table 3). 
Table 2

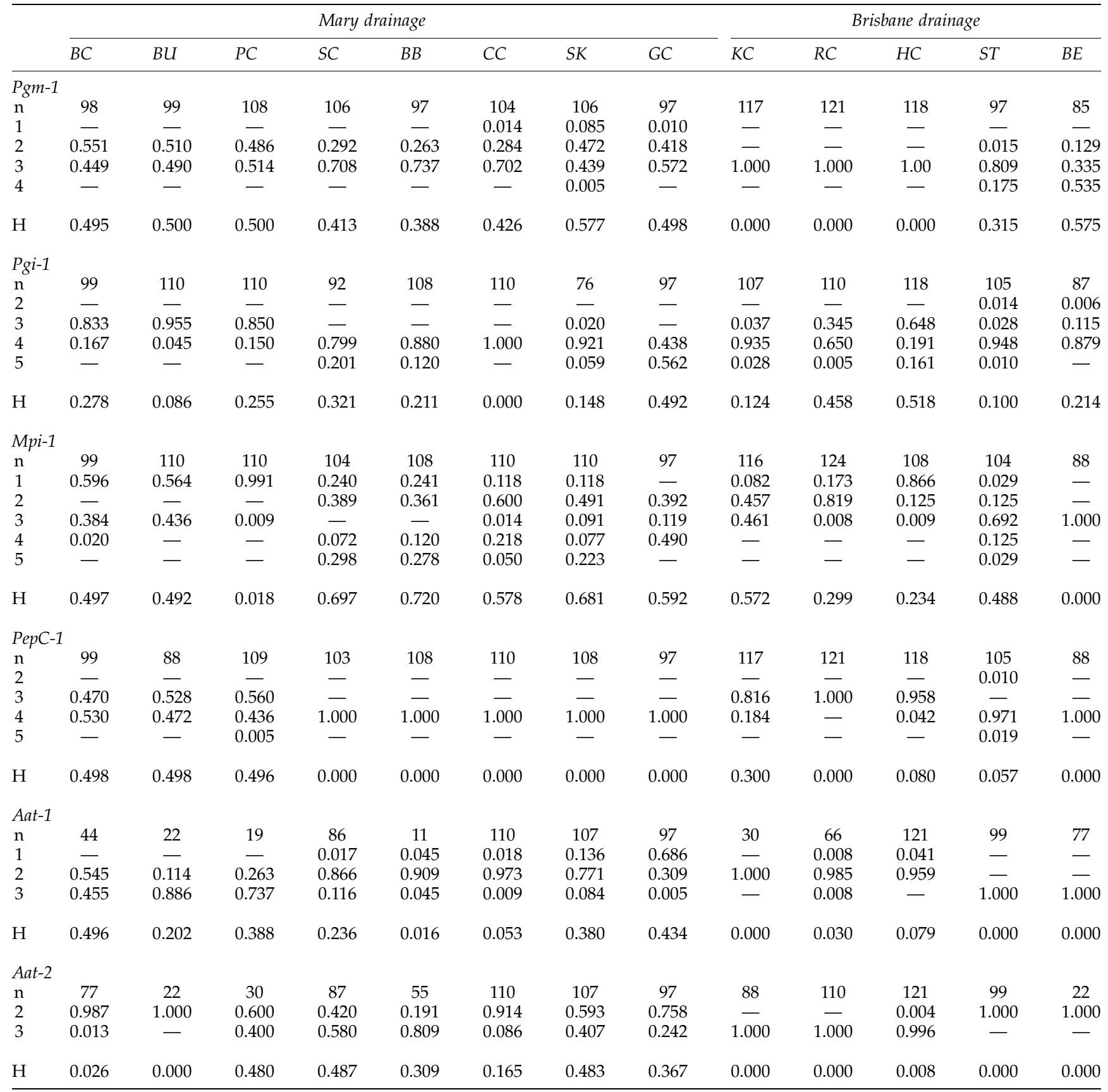

Table 3

$\begin{array}{llllllllllllllllllllllllllllllllllllllllll}1 & 1 & 1 & 1 & 1 & 2 & 2 & 2 & 2 & 2 & 2 & 2 & 3 & 3 & 3 & 3 & 3 & 3 & 3 & 4 & 4 & 4 & 4 & 4 & 4 & 4 & 4 & 5 & 5 & 5 & 5 & 5 & 5 & 5 & 5 & 6 & 6 & 6 & 6 & 6 & 6\end{array}$ $\begin{array}{llllllllllllllllllllllllllllllllllllllllllllll}1 & 3 & 8 & 9 & 2 & 7 & 8 & 8 & 8 & 1 & 3 & 5 & 5 & 6 & 6 & 7 & 0 & 0 & 2 & 3 & 3 & 5 & 6 & 1 & 2 & 2 & 3 & 3 & 6 & 7 & 9 & 1 & 2 & 2 & 3 & 5 & 5 & 7 & 7 & 0 & 1 & 1 & 2 & 2 & 2\end{array}$ $\begin{array}{llllllllllllllllllllllllllllllllllllllllllllllll}1 & 6 & 5 & 7 & 7 & 0 & 0 & 1 & 0 & 4 & 6 & 3 & 7 & 2 & 5 & 4 & 7 & 1 & 3 & 6 & 1 & 6 & 9 & 7 & 0 & 1 & 0 & 3 & 2 & 3 & 9 & 1 & 8 & 6 & 8 & 9 & 4 & 2 & 5 & 0 & 3 & 0 & 2 & 5 & 1 & 4 & 8\end{array}$ Pa1 A A A C T T G A T T G C C T A C A C T A A A C C G G G G T A T A G T A C A T T T A C T T T A C $\mathrm{Pa} 2$

$\mathrm{Pa} 3$

$\mathrm{Pa} 4 \quad \mathrm{G}$

Pa5 G G

Pa6

$\mathrm{Pa} 7$

Pa8

Pa10

Pa11

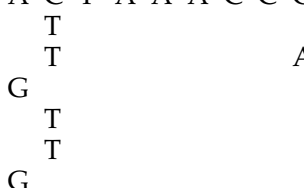

G
A

G
G

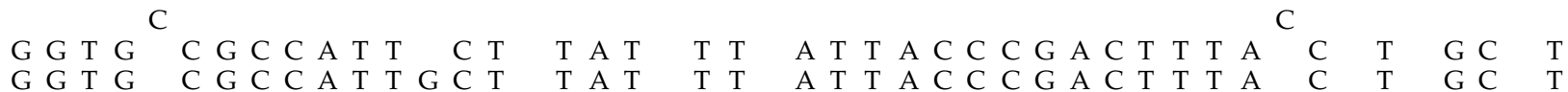

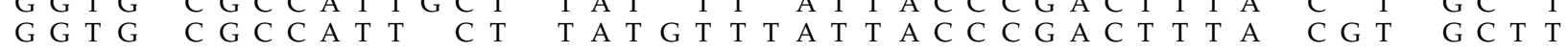

